KREATIF

Jurnal Ilmiah

Prodi Manajemen Universitas Pamulang
ISSN: 2339-0689 (Print), ISSN 2406-8616 (Online)

Volume 7, No 1 Juni 2019, (Halaman 80-92)

Tersedia online di http://openjournal.unpam.ac.id/index.php/kreatif

\title{
PENGARUH DEBT TO EQUITY RATIO (DER), CURRENT RATIO (CR), RETURN ON ASSET (ROA) DAN RETURN ON EQUITY (ROE)TERHADAP HARGA SAHAM DAN IMPLIKASINYA TERHADAP RETURN SAHAM PADA INDUSTRI PENERBANGAN \\ (Studi Kasus Pada Perusahaan Maskapai Asia)
}

\author{
Dede Hendra \\ Program Studi Manajemen \\ Universitas Pamulang \\ dosen02272@unpam.ac.id
}

Tujuan penelitian ini bertujuan untuk mengetahui ada atau tidaknya Pengaruh DER, CR, ROA dan ROE Terhadap Harga Saham Dan Implikasinya Terhadap Return Saham yang terjadi di Industri Penerbangan (studi kasus pada perusahaan Maskapai Asia). Jenis penelitian ini adalah deskriptif kuantitatif dan sumber data yang digunakan yaitu data primer dan data skunder.

Metode yang digunakan yaitu metode kuantitatif dengan alat analisa rasio dan analisis regresi data panel (Eviews System) dengan tingkat signifikan 5\%.

Hasil penelitian ini, menerangkan bahwa secara parsial DER berpengaruh signifikan terhadap Harga Saham, sedangkan CR, ROA dan ROE tidak berpengaruh terhadap Harga Saham. Secara simultan, DER, CR, ROA dan ROE berpengaruh signifikan terhadap Harga Saham yaitu sebesar 96,17\%, sementara Harga Saham tidak memberikan pengaruh terhadap Return Saham.

Kata Kunci : DER, CR, ROA, ROE, Harga Dan Retur Saham.

\section{ABSTRACT}

The research was purpose to acknowledge wether or not there was the influence o DER, CR, ROA, as well as ROE toward Shares Price, and the implication toward Shares Return on Aviation Industry (case study on Asian Airlines Company).

This research is considered as descriptive quantitative and the data sources used were primary and secondary data. The research methodology applied was quantitative method by using ratio analysis tool and regression analysis data panel (Eviews System) with significant level amounting to $5 \%$.

The result of this research declared that DER significantly gave impact to Shares Price, whereas $C R, R O A$ and ROE did not affect Shares Price. Simultaneously, DER, CR, ROA and ROE significantly affected Shares Price amounting to 96,17\%, nevertheless, Shares Price did not affect Shares Return.

Keywords $\quad$ :DER, CR, ROA, ROE, Shares Price and Shares Return.

\section{PENDAHULUAN}

\section{A. Latar Belakang}

Rasio keuangan merupakan gambaran keseluruhan atas kondisi keuangan perusahaan pada periode tertentu, rasio keuangan juga merupakan informasi untuk para stakeholder dalam menilai, mengevaluasi kinerja perusahaan secara keseluruhan dan memprediksi kemungkinan yang akan datang. Rasio keuangan dapat digunakan untuk mengevaluasi kinerja perusahaan dan dapat menghubungkan berbagai laporan sehingga kondisi keuangan perusahaan dapat dilihat hasilnya dan 
dapat diinterpretasikan. Disamping itu juga, efektivitas dan manajemen modal usaha yang diberikan investor merupakan unsur penting dalam perjalanan sebuah perusahaan baik perusahaan jasa atau perusahaan manufaktur, hal ini bertujuan agar sumber daya yang ada sesuai dengan ketentuan yang sudah direncanakan. Penggunaan investasi perusahaan harus dengan efektif agar profitabilitas perusahaan dapat dicapai dengan maksimal. Jika perusahaan tidak mampu mengelola investasinya, maka akan berdampak negatif, bahkan perusahaan tersebut akan mengalami kerugian. Dengan demikian, agar perusahaan dapat mengelola investasinya dengan baik, maka diperlukan alat untuk menganalisinya yaitu rasio.

Rasio merupakan sebagai alat ukur bagi perusahaan untuk menganalisa laporan keuangan yang dikelola perusahaan, sehingga posisi keuangan perusahaan dapat digambarkan dari periode ke periode berikutnya. Dengan bantuan tersebut pihak internal perusahaan dapat mengambil keputusan yang baik dan menguntungkan bagi perusahaan. Dengan pengelolaan modal usaha inilah perusahaan dapat memberikan kepuasan kepada para pemilik modal atau investor sehingga tingkat pengembalian yang mereka terima dapat sesuai dengan estimasi yang sudah ditetapkan.

Analisis rasio dilakukan dengan membandingkan antara neraca dan laba rugi perusahaan. DER, CR, ROA dan ROE merupakan jenis rasio yang sering digunakan oleh investor dalam mengukur kemampuan perusahaan menghasilkan keuntungan.

Di abad ini, mode transportasi mengalami kemajuan yang signifikan, hal ini ditentukan dengan berbagai upaya yang dilakukan oleh setiap negara untuk menciptakan dan melakukan inovasi disetiap lini transportasi khususnya industri penerbangan. Dengan semakin meningkatnya industri pada sektor penerbangan tentunya akan membawa pengaruh besar terhadap perkembangan dunia transportasi baik dalam negeri ataupun luar negeri, dari mulai terciptanya lapangan kerja baru. Namun, tuntutannya pun semakin tinggi terutama untuk internal perusahaan tersebut.

Berdasarkan gambaran diatas, peneliti tertarik untuk meneliti mengenai, "DER, CR, ROA dan ROE Terhadap Harga Saham Dan Implikasinya Terhadap Retur Saham Pada Industri Penerbangan (Studi Kasus Pada Perusahaan Maskapai Asia).

\section{B. Perumusan Masalah}

Sesuai dengan latar belakang diatas, maka dapat dirumuskan:

1. Apakah terdapat pengaruh antara DER terhadap Harga Saham?

2. Apakah terdapat pengaruh antara CR terhadap Harga Saham?

3. Apakah terdapat pengaruh antara ROA terhadap Harga Saham?

4. Apakah terdapat pengaruh antara ROE terhadap Harga Saham?

5. Apakah secara keseluruhan terdapat pengaruh antara DER, CR, ROA dan ROE terhadap Harga Saham?

6. Apakah terdapat pengaruh antara Harga Saham terhadap Retur Saham?

\section{Kerangka Pemikiran}

Peneliti mengumpulkan data yang terkait dengan DER, CR, ROA, ROE, Harga Saham dan Retur Saham dari objek yang diteliti dalam hal ini yaitu Industri Penerbangan yang berada di Asia, setelah data pendukung terkumpul lalu di rumuskan dengan menggunakan metodelogi penelitian guna mengetahui terdapat atau tidak terdapatnya pengaruh antara variabel X (DER, CR, ROA, ROE) terhadap 
variabel Y (Harga Saham) dan Y terhadap Z (Retur Saham). Dengan demikian, dasar pemikiran penelitian ini yaitu:

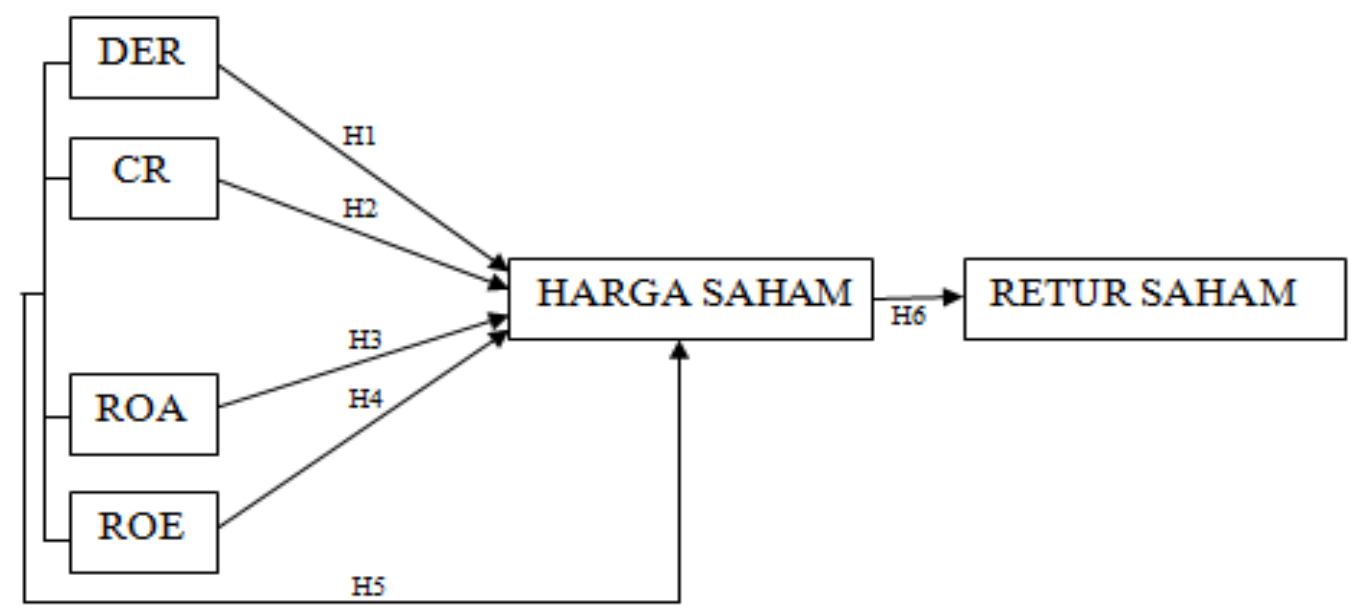

\section{Gambar 2.1 \\ Kerangka Berfikir}

\section{E. Hipotesis}

Ha $_{1} \rho \neq 0$ diduga adanya pengaruh DER terhadap Harga Saham.

$\mathrm{Ha}_{2} \rho \neq 0$ diduga adanya pengaruh CR terhadap Harga Saham.

$\mathrm{Ha}_{3} \rho \neq 0$ diduga adanya pengaruh ROA terhadap Harga Saham.

$\mathrm{Ha}_{4} \rho \neq 0$ diduga adanya pengaruh ROE terhadap Harga Saham.

Has $\rho \neq 0$ diduga adanya pengaruh DER, CR, ROA dan ROE secara keseluruhan terhadap Harga Saham.

Ha6 $\rho \neq 0$ diduga adanya pengaruh Harga Saham terhadap Retur Saham.

\section{TINJAUAN PUSTAKA}

\section{A. Debt to Equity Ratio (DER)}

DER merupakan rasio yang digunakan untuk menilai hutang dengan ekuitas. Rasio ini dicari dengan cara membandingkan antara seluruh hutang, termasuk hutang lancar dengan seluruh ekuitas, Kasmir (2014:157).

DER = Total Utang (Debt)/Ekuitas (Equity).

\section{B. Current Ratio (CR)}

Current Ratio (CR) merupakan rasio untuk mengukur kemampuan perusahaanmembayar kewajiban jangka pendek atau utang yang segera jatuh tempo pada saat ditagih secara keseluruhan (Kasmir, 2014:134).

Berikut Rumus current ratio adalah : Current Ratio $=$ Aktiva Lancar : Utang Lancar

D. Return On Asset (ROA)

Menurut Kasmir dalam bukunya (2014:201), menuliskan bahwa ROA memiliki definisi sebagai nilai rasio dari aktiva yang digunakan dalam perusahaan (Kasmir, 2014:201). Berikut rumusnya, ROA = Laba Bersih Setelah Pajak/Total Aset x $100 \%$

\section{E. Return On Equity (ROE)}

Return On Equity (ROE) sebagai berikut bahwa hasil pengembalian ekuitas atau return on equity atau rentabilitas modal sendiri merupakan rasio untuk mengukur 
laba bersih sesudah pajak dengan modal sendiri (Kasmir,2013:204). ROE dapat dihitung dengan menggunakan rumus: $\mathrm{ROE}=$ Laba Bersih Setelah Pajak/Ekuitas $\mathrm{x}$ $100 \%$

F. Harga Saham

Harga saham menentukan kekayaan pemegang saham. Maksimalisasi kekayaan pemegang saham diterjemahkan menjadi memaksimalkan harga saham perusahaan (Brigham dan Houston, 2010:7).

\section{G. Retur Saham}

Menurut Fakhruddin (2008:169) menyatakan retur saham merupakan laba atas suatu investasi yang biasanya dinyatakan sebagai tarif persentase tahunan. Retur Saham menurut Jogiyanto (2009:201) rumus retur saham adalah RS = $P t-P t-1+D t / P t-1$. Sedangkan Brigham dan Houston (2006:410) berpendapat RS $=P 1-P 0 / P 0$.

Keterangan:

$P t$ atau $P 1=$ Price yaitu harga untuk waktu $\mathrm{t}$

$P t-1$ atau $P 0=$ Price, yaitu harga untuk waktu sebelumnya

$D t=$ Dividen periodik

\section{METODOLOGI PENELITIAN}

\section{A. Tempat dan Waktu Penelitian}

Penelitian ini dilakukan pada Industri Penerbangan atau Maskapai Penerbangan yang ada di Asia. Peneliti mengambil data skunder yaitu laporan keuangan perusahaan selama lima tahun yaitu periode 2012-2016 dan data di ambil dari website perusahaan, yahoo finance dan sebagian data diambil melalui website http://www.sahamok.com.

Penelitian ini dilakukan dari mulai pra-riset bulan Agustus 2017 yaitu mengumpulkan data dan informasi mengenai objek penelitian dan dilanjutkan dengan pengajuan proposal dan penelitian terhadap objek penelitian dilakukan selama tiga bulan (Agustus-Oktober 2017).

\section{B. Metode Penelitian}

Metode yang digunakan dalam penelitian ini yaitu metode penelitian deskriptif kuantitatif yang bertujuan untuk mengetahui hubungan secara parsial dan keseluruhan antara variabel $\mathrm{X}_{1}, \mathrm{X}_{2}, \mathrm{X}_{3}, \mathrm{X}_{4},(\mathrm{DER}, \mathrm{CR}, \mathrm{ROA}, \mathrm{ROE})$ terhadap variabel Y (Harga Saham) dan implikasinya terhadap variabel Z (Retur Saham) pada industri penerbangan atau perusahaan maskapai Asia pada periode 20122016.

\section{Populasi dan Sampel}

\section{Populasi}

Populasi merupakan seluruh karakteristik atau jumlah dari objek yang akan diteliti, Pada penelitian ini Industri Penerbangan Asia yang sudah go public sebagai populasinya.

\section{Sampel}

Hanya sepuluh perusahaan maskapai yang diteliti dalam penelitian ini dan laporan keuangannya terdapat di masing-masing situs perusahaan tersebut atau yahoo finance.

\section{Jenis dan Sumber Data}

\section{Data Primer}


Data primer merupakan sumber data yang diperoleh dari sumbernya langsung tanpa melalui perantara seperti opini, subjek baik secara invidu atau kelompok, melakukan langsung penelitian di perusahaan atau melakukan observasi langsung terhadap kejadian. Adapun dalam bukunya Sugiyono (2013:225) berpendapat data primer yaitu informasi yang berasal langsung dari sumbernya tanpa melalui perantara.

\section{Data Sekunder}

Data skunder merupakan sumber yang tidak langsung memberikan data kepada pengumpul data, misalnya lewat orang lain atau lewat dokumen (Sugiyono, 2013:225). Dengan demikian, data skunder adalah data yang diperoleh secara tidak langsung seperti bukti, historis yang sudah di arsipkan dan catatan-catatan lainnya yang memberikan informasi. Dalam penelitian ini data diproleh dari situs emiten atau dari yang lainnya seperti yahoo finance \& google finance.

\section{E. Metode Analisis Data}

\section{F. Analisis Deskriptif}

Analisa ini bertujuan untuk mengetahui gambaran dari masing-masing variabel yang diteliti, sehingga akan lebih mudah dalam pengujian selanjutnya.

\section{G. Pengujian Kesesuaian Model}

Uji ini menggunakan sistem eviews dengan model sebagai berikut:

d. Model Common Effect

e. Model Fixed Effect

f. Model Random Effect

H. Pemilihan Model Regresi Data Panel

Untuk memilih model ini menggunakan eviews, yaitu:

a. Uji Chow

b. Uji Hausman

\section{Pengujian Hipotesis}

\section{a. Uji t}

Dengan melakukan uji t ini peneliti dapat menjelaskan pengaruh variabel independen secara parsial terhadap variabel dependen dan intervening, sehingga dapat diketahui tingkat signifikasi masing-masing variabel yang diteliti.

b. Uji F

Fungsi uji $\mathrm{F}$ untuk mengetahui besaran pengaruh variabel $\mathrm{X}$ terhadap variabel $Y$ secara keseluruhan dengan melihat nilai $F_{\text {hitung }}$ dengan nilai $F_{\text {tabel. }}$.

c. Uji Koefisien Determinasi $\left(\mathrm{R}^{2}\right)$

Agar mempermudah peneliti mengetahui pengaruh variabel $\mathrm{X}$ terhadap $\mathrm{Y}$ secara keseluruhan, maka analisis yang digunakan adalah metode statistik Koefisien Determinasi, dalam penelitian ini datanya diolah dengan sistem Eviews8.

\section{HASIL DAN PEMBAHASAN}

\section{A. Analisis Statistik Deskriptif}

Analisis statistik deskriptif ini berfungsi untuk menganalisis dan menyajikan data kuantitatif dengan tujuan untuk mengetahui sampel dari penelitian. Berikut adalah gambaran umum dari statistik deskriptif dari variabel yang diteliti sebagai berikut: 
Tabel 4.17 Hasil Uji Statistik Deskriptif Variabel Independen, Intervening Dan Dependen

\begin{tabular}{|c|c|c|c|c|c|}
\hline Variabel & $N$ & Minimum & Malsinum & Mean & Std. Deriation \\
\hline $\operatorname{DER}(\mathrm{Xl})$ & 50 & 0.668005 & 9.912335 & 3.075414 & 2.110695 \\
\hline $\operatorname{CR}(\mathrm{X} 2)$ & 50 & 0.233366 & 1.809968 & 0.813694 & 0.434211 \\
\hline $\mathrm{ROA}(\mathrm{X} 3)$ & 50 & -0.118497 & 0.171581 & 0.028070 & 0.051152 \\
\hline $\mathrm{ROE}(\mathrm{X} 4)$ & 50 & -0.419795 & 0.477378 & 0.053473 & 0.160723 \\
\hline HARGA SH (Y) & 50 & 0.000000 & 7130.000 & 598.4406 & 1666.333 \\
\hline RETURNSH (Z) & 50 & -0.525735 & 1.467391 & 0.035796 & 0.378397 \\
\hline
\end{tabular}

Sumber: Hasil output Data Eviews v. 8

Atau dengan kata lain sebagai berikut:

$\begin{array}{ccccccc}\text { KETERANGA } & \text { DER } & \text { CR } & \text { ROA } & \text { ROE } & \text { HARGA } & \text { RETUR } \\ \text { Minimum } & 0,66800 & 0,23336 & - & - & 0,00000 & - \\ \text { Maksimum } & 9,91233 & 1,80996 & 0,17158 & 0,47737 & 7130,00 & 1,46739 \\ \text { Rata-Rata } & 3,07541 & 0,81369 & 0,02807 & 0,05347 & 598,440 & 0,03579 \\ \text { St. Deviasi } & 2,11069 & 0,43421 & 0,05115 & 0,16072 & 1666,33 & 0,37839\end{array}$

\section{B. Pengujian Kesesuaian Model}

\section{Model Common Effect}

Tabel 4.18 Model Common Effect pengaruh DER, CR, ROA dan ROE terhadap Harga Saham

\begin{tabular}{crlll}
\hline \hline Variable & Coefficient & Std. Error & t.Statistic & Prob \\
\hline \hline C & -1886.819 & 722.4927 & -2.611541 & 0.0122 \\
DER & 628.1593 & 119.6353 & 5.250620 & 0.0000 \\
CR & 860.0053 & 571.9540 & 1.503627 & 0.1397 \\
ROA & -18503.20 & 8652.519 & -2.138476 & 0.0379 \\
ROE & 6975.704 & 2765.035 & 2.522826 & 0.0152 \\
\hline \hline R-squared & 0.421083 & Mean dependentvar & 598.4406 \\
Adjusted R-squared & 0.369623 & S.D. dependent var & 1666.333 \\
S.E. of regression & 1323.006 & Akaike infocriterion & 17.30784 \\
Sum squared resid & 78765548 & Schwarz criterion & 17.49904 \\
Log likelihood & -427.6960 & Hannan-Quinncrter. & 17.38065 \\
F-statistic & 8.182825 & Durbin-Watsonstat & 0.839068 \\
Prob(F-statistic) & 0.000048 & & & \\
\hline \hline
\end{tabular}

Sumber: output eviews 8.0 


\section{Model Fixed Effect}

\section{Tabel 4.19 Model Fixed Effect pengaruh DER, CR, ROA dan ROE terhadap} Harga Saham

\begin{tabular}{|c|c|c|c|c|}
\hline Variable & Coefficient & Std. Error & t-Statistic & Prob. \\
\hline C & 1069.014 & 437.8287 & 2.441627 & 0.0197 \\
\hline DER & -138.4869 & 74.67995 & -1.854406 & 0.0719 \\
\hline CR & -36.02437 & 374.8066 & -0.096115 & 0.9240 \\
\hline ROA & .760 .2956 & 3390.571 & $=0.224238$ & 0.8238 \\
\hline ROE & 111.9287 & 967.7480 & 0.115659 & 0.9086 \\
\hline \multicolumn{5}{|c|}{ Effects Specification } \\
\hline \multicolumn{5}{|c|}{ Cross-section fixed (dummy variables) } \\
\hline R-squared & 0.961666 & \multicolumn{2}{|c|}{ Mean dependentvar } & 598,4406 \\
\hline Adjusted R-squared & 0.947823 & \multicolumn{2}{|c|}{ S.D. dependentvar } & 1666.333 \\
\hline S.E. of regression & 380.6295 & \multicolumn{2}{|c|}{ Akaike info criterion } & 14.95303 \\
\hline Sum squared resid & 5215636 & \multicolumn{2}{|c|}{ Schwarz criterion } & 15.48839 \\
\hline Log likelihood & .359 .8256 & \multirow{2}{*}{\multicolumn{2}{|c|}{$\begin{array}{l}\text { Hannan-Quinn criter. } \\
\text { Durbin-Wats on stat }\end{array}$}} & 15.15690 \\
\hline F-statistic & 69.46975 & & & 2.390228 \\
\hline Prob(F-statistic) & 0.000000 & & & \\
\hline
\end{tabular}

Sumber: output eviews 8.0

\section{Model Random Effect}

Tabel 4.20 Model Random Effect pengaruh DER, CR, ROA dan ROE terhadap Harga Saham

\begin{tabular}{|c|c|c|c|c|}
\hline Variable & Coefficient & Std. Error & t-Statistic & Prob. \\
\hline C & 895.3089 & 597.6745 & 1.497987 & 0.1411 \\
\hline DER & -78.02374 & 72.28668 & -1.079365 & 0.2862 \\
\hline CR & -41.17636 & 360.7944 & -0.114127 & 0.9096 \\
\hline ROA & $-1701,547$ & 3357.882 & -0.506732 & 0.6148 \\
\hline ROE & 455.4465 & 961.3935 & 0.473736 & 0.6380 \\
\hline \multicolumn{5}{|c|}{ Effects Specification } \\
\hline & & & S.D. & Rho \\
\hline Cross-section random & & & 1329.546 & 0.9242 \\
\hline Idiosyncraticrandom & & & 380.6295 & 0.0758 \\
\hline \multicolumn{5}{|c|}{ Weighted Statistics } \\
\hline R-squared & 0.040350 & \multirow{5}{*}{\multicolumn{2}{|c|}{$\begin{array}{l}\text { Mean dependent var } \\
\text { S.D. dependent var } \\
\text { Sum squared resid } \\
\text { Durbin-Wats onstat }\end{array}$}} & 75.99843 \\
\hline Adjusted R-squared & -0.044953 & & & 404.1483 \\
\hline S.E. of regression & 413.1322 & & & 7680520. \\
\hline F-statistic & 0.473018 & & & 1.718969 \\
\hline Prob(F-statistic) & 0.755252 & & & \\
\hline \multicolumn{5}{|c|}{ Unweighted Statistics } \\
\hline R-squared & -0.110035 & \multirow{2}{*}{\multicolumn{2}{|c|}{$\begin{array}{l}\text { Mean dependent var } \\
\text { Durbin-Wats on stat }\end{array}$}} & 598.4406 \\
\hline Sum squared resid & $1.51 E+08$ & & & 0.480439 \\
\hline
\end{tabular}

Sumber: output eviews 8.0 


\section{Pemilihan Model Regresi Data Panel}

\section{Uji Chow}

Tabel 4.21 Hasil Uji Chow

\begin{tabular}{|lc|}
\hline \multicolumn{1}{|c|}{ Keterangan } & Hasil \\
\hline F binmg & 56,4 \\
\hline$F_{\text {tabel }}$ & 2,15 \\
\hline
\end{tabular}

Sumber: hasil output dari eviews 8.0

Tabel diatas menjelaskan bahwa nilai $\mathrm{F}_{\text {hitung }}$ dari hipotesis pengaruh $\mathrm{DER}, \mathrm{CR}$, ROA dan ROE terhadap Harga Saham lebih besar daripada $F_{\text {tabel }}$ yaitu $F_{\text {hitung }}$ sebesar 56,4 dan $\mathrm{F}_{\text {tabel }}$ sebesar 2,15, artinya $\mathrm{H}_{0}$ tidak diterima dan $\mathrm{H}_{1}$ diterima, Dengan demikian, berdasarkan tabel 4,24 diatas pemilihan model dalam uji chow yang dipilih yaitu Fixed Effect Model

\section{Uji Haumen}

Tabel 4.23 Hasil Uji Hausman

\begin{tabular}{|lc|}
\hline \multicolumn{1}{|c|}{ Keterangan } & Hasil \\
\hline Chi Square & 12,013424 \\
\hline P Value & 0,0173 \\
\hline
\end{tabular}

Sumber: output eviews 8.0 dan data terlampir III

Menurut hasil tabel 4,23 nilai $\mathrm{P}_{\text {value }}$ adalah $0,0173<0.05, \mathrm{H}_{1}$ diterima dan $\mathrm{H}_{0}$ tidak diterima, artinya model Fixed Effect yang dipilih.

\section{Pengujian Hipotesis}

\section{Uji F (Simultan)}

Tabel 4.24 Uji F

Pengaruh DER, CR, ROA dan ROE terhadap Harga dan Harga Saham

\begin{tabular}{|c|c|c|c|c|}
\hline Variable & Coefficient & Std. Error & t-Statistic & Prob. \\
\hline$\stackrel{C}{D E R}$ & $\begin{array}{r}1069.014 \\
-138.4869\end{array}$ & $\begin{array}{l}437.8287 \\
74.67995\end{array}$ & $\begin{array}{r}2.441627 \\
-1.854406\end{array}$ & $\begin{array}{l}0.0197 \\
0.0719\end{array}$ \\
\hline CR & -36.02437 & 374.8066 & -0.096115 & 0.9240 \\
\hline ROA & -760.2956 & 3390.571 & -0.224238 & 0.8238 \\
\hline ROE & 111.9287 & 967.7480 & 0.115659 & 0.9066 \\
\hline \multicolumn{5}{|c|}{ Effects Specification } \\
\hline \multicolumn{5}{|c|}{ Cross-section fixed (dummy variables) } \\
\hline R-squared & 0.961666 & \multicolumn{2}{|c|}{ Mean dependent var } & 598,4406 \\
\hline Adjusted R-squared & 0.947823 & \multicolumn{2}{|c|}{ S.D. dependent var } & 1666.333 \\
\hline S.E. of regression & 380.6295 & \multicolumn{2}{|c|}{ Akaike info criterion } & 14.95303 \\
\hline Sum squared resid & 5215636 & \multicolumn{2}{|c|}{ Schwarz criterion } & 15.48839 \\
\hline Log likelinood & -359.8256 & \multirow{2}{*}{\multicolumn{2}{|c|}{$\begin{array}{l}\text { Hannan-Quinn criter. } \\
\text { Durbin-Watson stat }\end{array}$}} & 15.15690 \\
\hline F-statistic & 69.46975 & & & 2.390228 \\
\hline Prob(F-statistic) & 0.000000 & & & \\
\hline
\end{tabular}

Sumber: output eviews ver. 8.0 
Berdasarkan tabel 4.24 menunjukan bahwa nilai $\mathrm{F}_{\text {hitung }}$ yaitu sebesar 69,46975 sementara $F_{\text {tabel }}$ sebesar 2,15. Dengan demikiaan, $F_{\text {hitung }}>F_{\text {tabel }}$ dan probablitas yaitu $0,000000<0,05$ sehingga $\mathrm{H}_{1}$ diterima. Hal ini berarti bahwa variabel DER, CR, ROA dan ROE secara bersama-sama berpengaruh signifikan terhadap Harga Saham.

\section{Uji t (Parsial)}

Tabel 4.25 Pengaruh DER Terhadap Harga

\begin{tabular}{|c|c|c|c|c|}
\hline Variable & Coefficient & Std. Error & t-Statistic & Prob. \\
\hline $\mathrm{C}$ & 1014.369 & 192.3601 & 5.273283 & 0.0000 \\
\hline DER & -135.2431 & 60.23884 & -2.245114 & 0.0305 \\
\hline \multicolumn{5}{|c|}{ Effects Specification } \\
\hline \multicolumn{5}{|c|}{ Cross-section fixed (dummy variables) } \\
\hline R-squared & 0.961570 & \multirow{2}{*}{\multicolumn{2}{|c|}{$\begin{array}{l}\text { Mean dependentvar } \\
\text { S.D. dependentvar }\end{array}$}} & 598.4406 \\
\hline Adjusted R-squared & 0.951716 & & & 1666.333 \\
\hline S.E. of regression & 366.1529 & \multicolumn{2}{|c|}{ Akaike info criterion } & 14.83552 \\
\hline Sum squared resid & 5228651. & \multicolumn{2}{|c|}{ Schwarz criterion } & 15.25616 \\
\hline Log likelinood & -359.8879 & \multirow{2}{*}{\multicolumn{2}{|c|}{ Hannan-Quinn criter. }} & 14.99570 \\
\hline F-statistic & 97.58332 & & & 2.407295 \\
\hline Prob(F-statistic) & 0.000000 & \multicolumn{2}{|c|}{ Durbin-Wats onstat } & \\
\hline
\end{tabular}

Sumber: output eviews ver. 8.0

Dari tabel 4.25 menunjukan nilai $t_{\text {hitung }}$ DER sebesar -2,245114 (negatif), sementara nilai $t_{\text {tabel }}$ dengan angka signifikan $5 \%$ dan $\mathrm{df}=(\mathrm{n}$ $\mathrm{k})=50-1=49$ sebesar 1,67655, yang berarti nilai $\mathrm{t}_{\text {hitung }}>\mathrm{t}_{\text {tabel }}$ dan memiliki probabilitas $0,0305<0,05$, artinya $\mathrm{H}_{0}$ tidak diterima dan $\mathrm{H}_{1}$ diterima. Sehingga, hipotesis terdapat pengaruh yang signifikan antara DER Terhadap Harga Saham yang diterima.

\begin{tabular}{|c|c|c|c|c|}
\hline Variable & Coefficient & Std. Efror & t-Statistic & Prob. \\
\hline $\mathrm{C}$ & 420.2303 & 285.7094 & 1.470831 & 0.1494 \\
\hline CR & 219.0139 & 344.6208 & 0.635522 & 0.5288 \\
\hline \multicolumn{5}{|c|}{ Effects Specification } \\
\hline \multicolumn{5}{|c|}{ Cross-section fixed (dummy variables) } \\
\hline R-squared & 0.957048 & \multirow{2}{*}{\multicolumn{2}{|c|}{$\begin{array}{l}\text { Mean dependentvar } \\
\text { S.D. dependent var }\end{array}$}} & 598.4406 \\
\hline Adjusted R-squared & 0.946035 & & & 1666.333 \\
\hline S.E. of regression & 387.0965 & \multicolumn{2}{|c|}{ Akaike info criterion } & 14.94676 \\
\hline Sum squared resid & 5843905. & \multicolumn{2}{|c|}{ Schwarzcriterion } & 15.36741 \\
\hline Log likelihood & -362.6691 & \multirow{2}{*}{\multicolumn{2}{|c|}{$\begin{array}{l}\text { Hannan-Quinn criter. } \\
\text { Durbin-Watson stat }\end{array}$}} & 15.10695 \\
\hline F-statistic & 86.89902 & & & 2.563572 \\
\hline Prob(F-statistic) & 0.000000 & & & \\
\hline
\end{tabular}

Sumber: output eviews ver. 8.0 
Berdasarkan tabel 4.26, nilai $t_{\text {hitung }} \mathrm{CR}$ adalah 0,635522, sementara nilai $\mathrm{t}_{\text {tabel }}$ dengan angka signifikan $5 \%$ dan $\mathrm{df}=(\mathrm{n}-\mathrm{k})=50-1=49$ sebesar 1,67655 , yang berarti nilai $t_{\text {hitung }}>t_{\text {tabel }}$, sementara probabilitasnya $0,5288>0,05$, sehingga $\mathrm{H}_{0}$ yang diterima dan $\mathrm{H}_{2}$ tidak diterima. Jadi, CR tidak memberikan pengaruh terhadap variabel Y yaitu Harga Saham.

Tabel 4.27 Pengaruh ROA Terhadap Harga Saham

\begin{tabular}{|c|c|c|c|c|}
\hline Variable & Coefficient & Std. Efror & t-Statistic & Prob. \\
\hline C & 582.2897 & 76.18039 & 7,643563 & 0.0000 \\
\hline ROA & 575.3860 & 1879.327 & 0.306166 & 0.7611 \\
\hline \multicolumn{5}{|c|}{ Effects Specification } \\
\hline \multicolumn{5}{|c|}{ Cross-section fixed (dummy variables) } \\
\hline R-squared & 0.956707 & \multirow{2}{*}{\multicolumn{2}{|c|}{ Mean dependent var }} & 598,4406 \\
\hline Adjusted R-squared & 0.945607 & & & 1666.333 \\
\hline S.E. of regression & 388.6290 & \multicolumn{2}{|c|}{$\begin{array}{l}\text { S.D. dependent vaf } \\
\text { Akaike info criterion }\end{array}$} & 14.95467 \\
\hline Sum squared resid & 5890268. & \multicolumn{2}{|c|}{ Schwarz criterion } & 15.37531 \\
\hline Log likelihood & -362.8667 & \multirow{2}{*}{\multicolumn{2}{|c|}{$\begin{array}{l}\text { Hannan-Quinn crter. } \\
\text { Durbin-Wats on stat }\end{array}$}} & 15.11485 \\
\hline F-statistic & 86.18433 & & & 2.534564 \\
\hline Prob(F-statistic) & 0.000000 & & & \\
\hline
\end{tabular}

Sumber: output eviews ver. 8.0

Dari tabel 4.27 diatas menjelaskan $t_{\text {hitung }}$ Return On Asset (ROA) sebesar 0,306166, sementara nilai $t_{\text {tabel }}$ dengan angka signifikan $5 \%$ dan $\mathrm{df}=(\mathrm{n}-\mathrm{k})=50-1=49$ sebesar 1,67655, yang berarti nilai $\mathrm{t}_{\text {hitung }}<\mathrm{t}_{\text {tabel }}$, probabilitasnya sebesar $0,7611>0.05$, jadi $\mathrm{H}_{0}$ yang diterima dan $\mathrm{H}_{3}$ tidak diterima. Sehingga, hipotesis yang menyatakan tidak terdapat pengaruh antara ROA terhadap Harga Saham yang diterima.

\begin{tabular}{ccccc}
\multicolumn{5}{c}{ Tabel 4.28 Pengaruh ROE Terhadap Harga Saham } \\
\hline \hline Variable & Coefficient & Std. Error & t-Statistic & Prob. \\
\hline \hline C & 577.3426 & 61.00085 & 9.464501 & 0.0000 \\
ROE & 394.5562 & 508.4619 & 0.775980 & 0.4424 \\
\hline \multicolumn{5}{c}{} \\
\hline \hline Cross-section fixed (dummy variables) \\
\hline \hline R-squared & 0.957263 & Mean dependentvar & 598.4406 \\
Adjusted R-squared & 0.946305 & S.D. dependentvar & 1666.333 \\
S.E. of regression & 386.1264 & Akaike info criterion & 14.94175 \\
Sum squared resid & 5814650. & Schwarzcriterion & 15.36239 \\
Log likelihood & -362.5436 & Hannan-Quinncrter. & 15.10193 \\
F-statistic & 87.35586 & Durbin-Watsonstat & 2.502646 \\
Prob(F-statistic) & 0.000000 & & \\
\hline
\end{tabular}

Sumber: output eviews ver. 8.0

Hasil dari uji t ini menunjukan nilai thitung ROE sebesar 0,775980, 
sementara nilai $\mathrm{t}_{\text {tabel }}$ dengan angka signifikan $5 \%$ dan $\mathrm{df}=(\mathrm{n}-\mathrm{k})=50-1=$ 49 sebesar 1,67655 , yang berarti nilai $t_{\text {hitung }}>t_{\text {tabel, }}$, probabilitasnya $0,4424>0,05$, artinya $\mathrm{H}_{0}$ yang diterima dan $\mathrm{H}_{4}$ ditolak. Dengan demikian, di duga tidak adanya pengaruh antara ROE Terhadap Harga Saham menjadi hipotesis yang diterima.

\section{Tabel 4.29 Pengaruh Harga Saham Terhadap Retur Saham}

\begin{tabular}{lrlrl}
\hline \hline \multicolumn{1}{c}{ Variable } & Coefficient & Std. Error & t-Statistic & Prob. \\
\hline \hline C & -0.103891 & 0.115072 & -0.902833 & 0.3722 \\
HARGA_SAHAM & 0.000233 & 0.000167 & 1.399804 & 0.1695 \\
\hline \hline \multicolumn{4}{c}{ Effects Specification } \\
\hline Cross-section fixed (dummy variables) & \\
\hline \hline R-squared & 0.087396 & Mean dependentvar & 0.035796 \\
Adjusted R-squared & -0.146605 & S.D. dependent var & 0.378397 \\
S.E. ofregression & 0.405187 & Akaike info criterion & 1.222600 \\
Sum squared resid & 6.402869 & Schwarz criterion & 1.643245 \\
Log likelihood & -19.56500 & Hannan-Quinncrter. & 1.382784 \\
F-statistic & 0.373487 & Durbin-Watsonstat & 2.392888 \\
Prob(F-statistic) & 0.950832 & & \\
\hline \hline
\end{tabular}

Sumber: output eviews ver. 8.0

Hasil dari uji t ini sesuai tabel 4.29 memberikan gambaran bahwa nilai thitung Harga Saham 1,399804, sementara nilai tabel yang tingkat signifikannya $5 \%$ dan $\mathrm{df}=(\mathrm{n}-\mathrm{k})=50-1=49$ sebesar 1,67655 , yang berarti nilai thitung $\left\langle\mathrm{t}_{\text {tabel, }}\right.$, angka0ptóbabilitas $0,1695>$, artinya $\mathrm{H}_{0}$ yang iterima dan $\mathrm{H}_{5}$ tidak diterima. Dengan demikian, di duga tidak adanya pengaruh antara Harga Saham Terhadap Retur Saham adalah hipotesis yang diterima. 


\section{Uji Koefisien Determinasi $\left(\mathbf{R}^{2}\right)$}

Tabel 4,30 Uji Koefisien Determinasi $\left(R^{2}\right)$

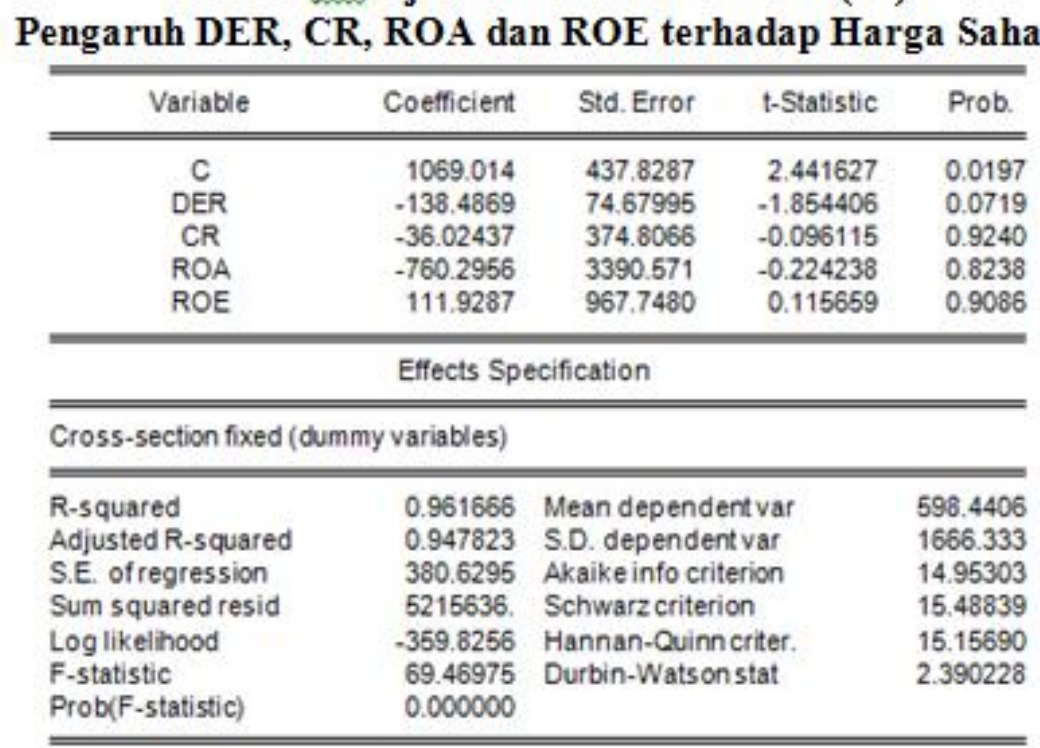

Sumber: output eviews ver. 8.0

Berdasarkan tabel 4,30 menunjukan besarnya nilai adjusted $\mathrm{R}^{2}$ sebesar 0,961666 yang berarti variasi empat variabel independen yaitu DER, CR, ROA dan ROE mampu menjelaskan 96,17\% berpengaruh terhadap variabel intervening nya dan sisanya 3,83\% dipengaruhi oleh variabel yang tidak diteliti.

\section{KESIMPULAN}

Berdasarkan hasil dari penelitian yang telah dilakukan berbagai pengujian pada bab sebelumnya maka penelitian ini dapat disimpulkan bahwa:

1. DER berpengaruh terhadap Harga Saham.

2. CR tidak berpengaruh terhadap Harga Saham.

3. ROA tidak berpengaruh terhadap Harga Saham.

4. ROE tidak berpengaruh terhadap Harga Saham.

5. DER, CR, ROA dan ROE secara keseluruhan berpengaruh terhadap Harga Saham. DER, CR, ROA dan ROE mempengaruhi 96,17\% terhadap Harga Saham, sementara 3,83\% dipengaruhi oleh jenis variabel yang tidak diteliti.

6. Harga Saham tidak berpengaruh terhadap Return Saham.

\section{DAFTAR PUSTAKA}

Brigham, Eugene.F and Joel F. Houston, (2006). Dasar-Dasar Manajemen Keuangan", Alih Bahasa Ali Akbar Yulianto, Edisi sepuluh. Jakarta : Salemba Empat.

Brigham, Eugene.F and Joel F. Houston, (2010). Dasar-Dasar Manajemen Keuangan, Alih Bahasa Ali Akbar Yulianto, Edisi Kesebelas, Jilid I \& II. Jkarta: Salemba Empat.

Fakhruddin, Hendy M. (2008). Istilah Pasar Modal A-Z, Jakarata: Elex Media Komputindo.

Ghozali, Imam. (2011). Aplikasi Analisis Multivariate Dengan Program SPSS". Semarang: Badan Penerbit Universitas Diponegoro.

Jogiyanto. (2009). Teori Portofolio dan Analisis Investasi”, Edisi Ketujuh, Yogyakarta:

BPFE-Yogyakarta. 
Kasmir. (2014). Analisis Laporan Keuangan Jakarta: PT. Rajawali Persada.

Kasmir. (2013). Analisis Laporan Keuangan. Edisi Pertama, Cetakan ke-6. Jakarta: PT. Rajawali Persada.

Riduwan. (2012). Metode \& Teknik Menyusun Proposal Penelitian. Bandung: Alfabeta.

Sugiyono. (2013). Metode Penelitian Kuantitatif Kualitatif dan $R \& D$. Bandung: Alfabeta. 